\title{
Connecting the Anthropology of Aging and Occupational Therapy/Occupational Science: Interdisciplinary Perspectives on Patterns and Meanings of Daily Occupation
}

\author{
Margaret A. Perkinson, PhD
}

Sherylyn Briller, $P h D$

As highlighted by funding priorities articulated in the National Institutes on Health (NIH) Roadmap (2003), collaborations across disciplines represent today's intellectual life at the cutting edge. Gerontologists, and gerontological anthropologists in particular, are well-positioned to advocate for and assist in the development of innovative models of interdisciplinary scholarship, given our long-standing tradition of working across disciplinary lines in the attempt to understand aging in all its complexity. Anthropologists of aging who work within the anthropology-occupational science/occupational therapy (anthro-OT) intersection are well-versed in addressing these issues. Past Society for Medical Anthropology President Marcia Inhorn (2007) identified the intersection between anthropology and occupational therapy/occupational science (the scientific discipline that informs the application or practice of occupational therapy) as one of the ten most promising areas for future research, and that intersection represents one of the primary foci for the 2009 SMA conference, "Medical Anthropology at the Intersection: Celebrating 50 Years of Interdisciplinarity." In this $A A Q$ special issue, we highlight recent dialogue between the fields of anthropology, gerontology and occupational science/therapy to gain a more nuanced understanding of the everyday experiences or "occupations" of aging and to convey the "lived experiences" of confronting the challenges entailed in conducting interdisciplinary work. This special issue contains overviews of papers presented in the conference session: "Aging and Activity: Patterns and Meanings of Daily Occupation," presented at the 2007 American Anthropological Association meetings in Washington, D.C. The session's papers illustrate the ways in which these fields continue to inform each other and identify areas for future work. We hope this issue will contribute to the expansion and refinement of this dialogue.

A brief overview of prior and current collaborations between the above-mentioned fields will provide context for the papers in this issue. Anthropology and occupational therapy/ occupational science share major components of their identities as disciplines. Both fields emphasize the importance of a holistic approach to the understanding of meanings within context. As defined by its professional society, the American Occupational Therapy Association (AOTA), the contribution of occupational therapy (OT) as a field is in "... promoting the health and participation of people, organizations, and populations through engagement in occupation" (AOTA 2008, p.625). "Occupation" refers to participation in "activities ... of everyday life, named, organized, and given value and meaning by individuals and a culture. Occupation is everything people do to occupy themselves, including looking after themselves...enjoying life... and contributing to the social and economic fabric of their communities" (Law et al. 1997, p. 32). Occupational justice has emerged as a central, orienting concept of the discipline: “... the profession's concern with ethical, moral, and civic factors that can support or hinder health-promoting engagement in occupations and participation in home and community" (AOTA 2008, p. 630). Implicit in this orientation is an openness to expand beyond a strictly medical model and embrace community-based rehabilitation and socially constructed models of disability. Occupational therapy's increased attention to social and occupational justice (Kronenberg, Algado, \& Pollard 2005; Pollard, Sakellariou \& Kronenberg 2009) underscores its shared interests with anthropology in critical issues relating to social equality, social marginalization and the representation of diverse voices. A small but growing number of OT departments count anthropologists among their faculty, and a few leading scholars have advanced degrees in both fields.

Initial collaborations among anthropologists and OTs developed over time and eventually reached a critical tipping point at the 2006 Society for Applied Anthropology (SfAA) meetings in Vancouver, where Gelya Frank (anthropologist) and Ruth Zemke (occupational therapist) organized an invited double panel, "Occupation on the Edge: The New Discipline of Occupational Science in Dialogue with Anthropology," devoted to the anthro-OT connection. The high level of interest that these panels generated prompted the organization of a three-part anthroOT series of panels for the following 2006 Society for the Study of Occupation (SSO) meetings, held in St. Louis, MO, thereby reaching a larger audience of occupational therapists. Momentum continued to build as sessions showcasing the anthro-OT connection were held at subsequent AAA, SfAA, and SSO conferences. Practicing Anthropology devoted a special issue to anthropology and OT (Block, Frank, \& Zemke 2008), further highlighting the advancement of theory and practice across these disciplines. The most recent SfAA meetings, held in Santa Fe, March 2009, showcased ten 


\section{Features}

anthro-OT related sessions, with contributions from a world-wide assembly of scholars from the United States, Sweden, Japan, England, China, Brazil, Canada, and South Africa.

Given the intense level of interest and the numbers of persons involved, it was only a matter of time before this emerging movement crystallized into a special interest group. A document proposing the formation of the National Association for Practicing Anthropology (NAPA) Occupational Therapy and Occupational Science Interdisciplinary Special Interest group (NAPA OT-SIG) (Frank, 2007) summarized the ongoing interactions between anthropology and OT and provided the rationale for further collaborations. The proposal was accepted, and the interest group was officially approved by the NAPA Governing Council in 2007. As reported in the executive summary from this new interest group's first meeting, the NAPA OT-SIG currently focuses on (1) becoming an academic presence at conferences, building alliances and collaborations; and (2) developing an interdisciplinary field school in Guatemala for education and collaborative practice between anthropologists, occupational therapists, and disability studies scholars.

The NAPA-OT Field School in Antigua,

Guatemala was approved by both NAPA and AAA and will hold its inaugural session Summer 2009. Its intent is to "provide a setting where anthropologists and occupational therapists can study, practice, and learn together." Social justice and the political practice of OT across the life course provide the conceptual frameworks that undergird its three areas of focus: Neonatal Assessment and Early Child Development, Disability Studies, and CommunityBased Gerontology. The presence of the gerontological component underscores the importance of aging in this intellectual mix.

Aging issues have consistently been a part of the above-mentioned conference sessions and publications. Some individual papers in past conference sessions focused specifically on issues of older adults, such as Margaret Perkinson's series of papers on the "Exercise and Dementia Project," Wendy Wood's work on dementia, Susan Magasi's work on issues of nursing home residents, and Devva Kasnitz, Russell Shuttleworth, and Robert Pedlon's work on technology, aging, and disability. Others, while not focusing on older adults per se, discussed topics relevant to both aging experiences and community-based disability research (e.g., Cathy Lysack's work on community participation, marginalization, and disability and Elaine Gerber's work on community-based research with persons who are blind). Sherylyn Briller and Jayne Yatczak envisioned new models for cross-training opportunities and interdisciplinary career development for anthropologists preparing for careers in OT research and teaching. However, the 2007 AAA conference session that is the basis for this $A A Q$ special issue was the first session with a primary focus on old age to come out of the anthroOT connection.

The central premise of the "Aging and Activity: Patterns and Meanings of Daily Occupation" session was as follows: "The concept of daily occupation is the focus of the practice profession of occupational therapy and its basic discipline of occupational science. Occupations, broadly defined, refer to personally meaningful chunks of activity that are the basis of everyday routines, are organized within or in relation to social structures, and have cultural salience. The development of research on the organization of daily activity and its relationship to health and well-being promises to improve life opportunities for people of all ages. However, this research is particularly salient to older adults, who often find themselves marginalized, denied access to mainstream occupations. This panel was designed to bring together anthropologists and scholars in occupational therapy and occupational science to discuss interdisciplinary concepts, approaches, methods, and data as well as practice implications, in their work as it relates to age and wellness."

Two senior scholars in the fields of occupational science/occupational therapy (Charlotte Royeen) and anthropology and gerontology (Mark Luborsky) served as discussants for the session. Rather than simply providing feedback on individual papers, each of these discussants elected to make broader framing remarks about the emerging anthro-OT intersection and their longer-term vision for interdisciplinary scholarship in this area.

Charlotte Royeen, PhD, OTR, Dean of Doisy College of Health Sciences, Saint Louis University, presented the OT perspective. As a scholar coming to the anthropology meetings from another discipline, she highlighted the importance of using a common language to frame research questions and operationalize definitions of key concepts. Dr. Royeen considered shared terminology a necessary prerequisite, not only for discussions of aging and activity-related issues, but, more broadly, for the interplay of these fields and their shared research and practice agendas. Dr. Royeen concluded these remarks by expressing her enthusiasm for this crossdisciplinary dialogue and her desire to see it to continue to grow over time.

Mark Luborsky, PhD, Professor of Anthropology and Director of Aging and Health Disparities Research, Wayne State University Institute of Gerontology, employed a strikingly vivid metaphor, the exploration 


\section{Perkinson and Briller, continued from p. 26}

of a new house, to convey the experience of venturing into a new place (either physical or intellectual) and thoroughly exploring it, room-by room. This orienting metaphor enabled him to discuss quite eloquently how he viewed the "fun" (aka intellectual excitement) of throwing open the doors and seeing what one finds in these rooms. Upon entering each new room, one can see what is already there and the overall dimensions and characteristics of these spaces. Sometimes one knows about key aspects of what one will find there, and sometimes one is surprised as well. Opening these doors also presents opportunities to think about how the various "rooms" in the house fit together and can be coordinated over time. He captured the excitement that comes at the beginning of such an exploration and recommended paying close attention to all aspects of this discovery process, keeping the "big picture" in mind and never forgetting the fundamentals of each field - e.g., what makes the framing of a particular issue anthropological, and likewise for OT. The "good bones" of the anthro-OT house, with its strong foundation and supporting structures, should provide an appropriate environment that will foster the continued growth of our cross-disciplinary dialogue.

In spite of its time slot (i.e., the last morning of the conference), it was clear that the session had an impact. There was much post-session discussion in the hallway about individual papers, the discussants' comments, and where to go from here; so much so that several people expressed concern about making it to the airport in time to catch their flights. We, as the session organizers, took it as a good sign that this conversation continued, that there was enthusiasm for ongoing exploration of this linkage, and it fortified us for taking this work forward. We hope that you will enjoy reading about these issues, learning about what has been discussed so far, and adding your own voices and perspectives to extending this conversation.

\section{References:}

American Occupational Therapy Association (AOTA). 2008. Occupational Therapy practice framework: Domain $\mathcal{E}$ process. $2^{\text {nd }}$ edition. Bethesda, MD: The American Occupational Therapy Association, Inc.

Block, P., Frank, G. \& Zemke, R. 2008. Practicing Anthropology (Special issue on Anthropology and Occupational Therapy), 30(3).

Frank, G. 2007. Occupational Therapy \& Occupational Science Interdisciplinary Interest Group: A proposal to the National Association for the Practice of Anthropology.

Inhorn, M. 2007. Medical anthropology at the intersections. Medical Anthropology Quarterly, 21(3): 249-55.

Kronenberg, F., Algado, S. \& Pollard, N. 2005. Occupational therapy without borders. Edinburgh: Elsevier/Churchill Livingstone.

Law, M., Polatajko, H. Baptiste, W. \& Townsend, E. 1997. Core concepts of occupational therapy. In E. Townsend (Ed.), Enabling occupation: An occupational therapy perspective (pp. 29-56). Ottawa, ON: Canadian Association of Occupational Therapists.

Pollard, N., Sakellariou, D. \& Kronenberg, F. 2009. A political practice of occupational therapy. Edinburgh: Elsevier/ Churchill Livingstone.

Schatz, continued from page 27

the individuals' "life opportunities." In all likelihood, most of them will become practitioners, not researchers, but this experience allows them to see why evidence-based practice is important and how an interdisciplinary lens enhances both their field and others.

Harrod, continued from page 29

adults' interest in not only "doing something" but also "being someone", and for these participants, that meant being recognized as active, engaged, independent and therefore, vital contributing members within American society. Going forward in extending this research program, I look forward to drawing upon and integrating a variety of disciplinary perspectives that can inform this work from anthropology, gerontology, occupational science/occupational therapy, and technology studies, to list some relevant areas here. 